\title{
Voter Preferences, Local Party Competitiveness, Turnout, and Strategic Voting: Deterrents to Voting are Unequally Distributed
}

\author{
Fred Cutler ${ }^{1}$, Antony J Hodgson ${ }^{2}$, and Alex B. Rivard ${ }^{1}$ \\ ${ }^{1}$ University of British Columbia, Department of Political Science \\ ${ }^{2}$ University of British Columbia, Department of Mechanical Engineering \\ November 4, 2020
}

\begin{abstract}
Voters are deterred from casting a vote and more likely to vote strategically if their preferred choice is less competitive in the electoral district. We use 2019 Canadian Election Study data and find that respondents' answers to a 'How Likely are you to Vote' question depends on their estimate of their preferred party's local chances of winning, relative to other parties. We find this effect much more strongly among voters who believe voting is a "choice" rather than a "duty". Noting that this likely-to-vote measure is a more valid measurement of variation in propensity to turn out to vote than reported vote, we estimate that nearly 200,000 eligible voters in Canada in 2019 would have been "Certain to Vote" if they thought their preferred party was likely to win the district but were in fact not in that "Certain" category because they estimated their preferred party had less chance of winning than another party. The effect is much stronger when voters rank their party third or fourth in the district, rather than second. This deterrent effect on turnout from the competitiveness of voter's preferred party is concentrated among certain parties (NDP, Green, Peopyle's Party of Canada), meaning that voters with particular policy perspectives are systematically deterred from voting, relative to other voters. Furthermore, we find that strategic voting is also heavily concentrated among voters who prefer parties outside the nationally most competitive two parties.
\end{abstract}

\section{Introduction}

Casting a vote is perhaps the most fundamental manifestation of democratic equality, encapsulated in the phrase "One Person, One Vote". At one level, democratic equality is embodied in formal eligibility -a right to vote - and eligible citizens can choose whether or not to exercise this right. The other dimension, however, is equality of the effect of each vote, which is a function of institutions and political geography, and something that has forced its way into the judicial enforcement of the formal right to an equal vote. If a polity demonstrates any systematic deterrents to casting a ballot that result in differential abstention by sets of citizens with identifiable characteristics or preferences, it will be judged less democratic, less equal, and its policy outputs will be less representative. The same can be said about voting strategically: if the system means that particular sets of citizens 'hold their nose' to vote strategically then those citizens could be said to be unequal members of the polity in terms of electoral participation. While there are many trade-offs to be made in constitutional design, these differentials in turnout and strategic voting must be avoided in a democracy. 
Electoral systems are one of many potential institutional influences on who casts a vote and who votes nonsincerely, since they shape which parties and candidates compete for office, the number and distinctiveness of options available to voter, and the electoral geography in which voters find themselves. The formula translating votes to seats strongly affects how effective is a given voter's vote, conditional on her location and preferences. It is well established that there is a link between electoral systems and aggregate turnout and this works through the range and distinctiveness of the potential choices and the likelihood that voters' votes translate into representation (see (Wilford, 2017) and references therein). These two factors probably interact: Voters prefer choices that correspond to their preferences and the prospect that voting for one of these choices will result in the election of a candidate or party that shares those preferences. As either of these two factors diminishes, voters see less and less point in taking the time and making the emotional and cognitive investment to cast a ballot; the result is a lower probability of voting. In a less precise but more concise formulation: voters who feel a weaker connection from their choice to the outcome are less likely to bother going to the polls, or to vote sincerely once they get there.

There is no existing study that assesses these two factors - choice and likelihood of voting for a winner and their interaction, at the level of individual voters, using data on voters' preferences and their relative placement of their chosen party's competitiveness. Most of the evidence for the claims mentioned above comes from the aggregate level, comparing levels of turnout across different electoral systems that inherently produce more or less choice for voters and connect relatively more or fewer votes to an elected representative (Blais \& Carty, 1990; Karp \& Banducci, 1999; Banducci \& Karp, 2009; Söderlund, 2017; Blais \& Aarts, 2006; Norris, 1997; Brockington, 2004; Vowles et al., 2015; Endersby et al., 2002; Arnold, 2018; Curini \& Jou, 2016; Blais \& Carty, 1991). There is good Canadian and British individual-level evidence that riding competitiveness affects voters' propensity to vote, but it uses only the total competitiveness of the riding rather than voters' judgments about the relative competitiveness of their preferred party (Johnston et al., 2007; Vowles et al., 2015; Maeda, 2016). That evidence shows that where a voter lives can systematically affect whether they vote, but it does not show that supporters of certain parties or those with certain preferences are deterred from voting - or from voting sincerely as opposed to strategically - because their own preferred party is less competitive.

Here, we simply extend the arguments and logic of previous work to differentiate within districts between voters who think a vote for their preferred party will, or even might, make a difference, and those voters who may think their party is so uncompetitive in the district that there is a much weaker benefit to casting their vote.

We use survey data from the 2019 Canadian federal election to examine the link between how competitive is that voter's preferred electoral choice in their local district (riding) and the voter's likelihood of casting a vote. That is: are voters whose preferred choice is less likely to win the local seat less likely to turn out to vote or to vote sincerely rather than strategically? And secondarily, given the existing party system, does this result in supporters of some parties staying home or voting insincerely more than supporters of other parties?

We show that, despite the challenges of measuring a person's intent to cast a vote and the even more problematic measure of reported turnout after an election, Canadians both express a lower intention to vote and are less likely to turn out to vote if they think, and if it is objectively the case, that their preferred party (PP) is less likely to win the riding than another party. We also show that strategic voting is more common among supporters of some parties than others, meaning that voters with preferences for parties they think are more competitive are more likely to feel able to sincerely express their preferences than other voters. We hasten to add that although it may seem obvious that supporters of less competitive parties are more likely to vote strategically, this is worth demonstrating since the local district is the locus of strategic voting and it is perfectly possible that given the larger numbers of supporters of more competitive parties we could find more strategic voting among them, as a proportion of all voters. 


\section{Data}

Our principal source of data is the Canadian Election Study 2019. The CES is the most extensive, carefully conducted academic survey available with the data we require. The survey is now conducted both on the telephone and online, with the 2019 study providing data from over 37,000 interviews.

The CES design begins with a pre-election questionnaire (the "Campaign Period Survey", hereafter "PRE" in this paper) and then invites all respondents to also complete a post-election questionnaire (the "PostElection Survey" or "POST"). In 2019, the CES team judged 33,905 pre-election (PRE) responses to be complete and from attentive responders, with 8,313 of those respondents providing complete and attentive responses to the POST.

The key survey questions we use in this analysis are:

From the PRE:

- How likely the respondent thinks they are to vote

- Which party the voter intends to vote for

- Party and leader rating 'thermometers' (scores from 0 to 100), allowing us to determine the voter's preferred party and leader

- Respondents' estimate of the 'chances' of each party winning the local seat (scores from 0 to 100)

- Whether the voter considers the act of voting a duty or a choice

From the POST:

- Respondents' report of whether or not they voted

- Respondents' report of which party they voted for

In addition, the CES identifies the respondent's Federal Electoral District (riding), so we are able to merge official election results from both the 2015 and 2019 elections to assign to respondents an objective measure of the parties' competitiveness in the district based on either the previous or current election results. Nonetheless our focus is on voters' own judgment of the competitiveness of their chosen party, since that is what will drive their decision to vote or not, and we know that there is a good deal of wishful thinking in voters' forecasts. As long as there is a reasonably strong link between results from the previous election and voters' perceptions of their party's local chances (Blais \& Bodet, 2006), we are on solid ground in drawing a connection between the functioning of the electoral system and effects on voters' propensity to vote or to vote sincerely.

\section{Measurement}

\section{Measuring Turnout}

At the conceptual level, we wish to evaluate the effects of the local competitiveness of parties on intended or actual turnout, as well as on strategic voting. For turnout, ideally, we would have a validated, objective measurement of whether the survey respondent actually voted, but such a measure is unavailable in Canada (Achen, 2019).

Measurement of turnout with surveys is fraught. In general, the post-election reported vote rate in surveys considerably exceeds government-reported turnout figures. In 2019, Elections Canada reported $67 \%$ turnout, while in stark contrast $92.5 \%$ of the 8,313 respondents in the Canadian Election Study's postelection wave said that they had voted. This poses a problem for estimating the proportion of voters who fail to vote as a result of their preferred party's competitiveness. The source of the bias is that political 
interest and engagement drive both voting and participation in the survey, as well as the reluctance of some voters to report that they have not voted (e.g., due to the sense that they ought to have voted).

Fundamentally, the statistical problem is that among voters whose preferred party has little hope of winning, the ones who get through to the post-election interview will have unmeasured characteristics that make them more likely to appear in the post-election sample and to report having voted (whether truthfully or not). This is apparent from the paucity of those who say they are "Certain not to vote" in the sample - less than $2 \%$ - and the fact that among those respondents who claimed in the initial survey to be certain not to vote and nevertheless participated in the post-election interview, $20 \%$ report having voted!

So studies of turnout using data like these face a selection bias issue that will likely lead to underestimation of the effect of competitiveness because included are only those respondents who wanted to do the postelection interview and not their counterparts who did not. We therefore interpret any results based on the post-election Reported Vote results (hereafter, RV) with caution.

The pre-election question, asking voters to say how likely they are to vote (hereafter, LV), is similarly biased, but likely less so. The effect of political interest on recruitment to this first survey is likely weaker than its effect on attrition from pre- to post-election. And the question itself, prior to the election and worded to diminish a social desirability effect, gives us more variation in degree of commitment to voting than the post-election vote report.

The pre-election question is: "On election day, how likely are you to vote: Certain to vote, Likely to vote, Unlikely to vote, or Certain not to vote?". The response percentages are shown in Table 1.

$\begin{array}{ccc}\text { CES2019 Likelihood of Voting } & \% & \mathrm{~N} \\ \text { Certain to Vote } & 78 & 23359 \\ \text { Likely to Vote } & 16 & 4883 \\ \text { Unlikely to Vote } & 4 & 1159 \\ \text { Certain not to Vote } & 2 & 528\end{array}$

Table 1: CES 2019 Pre-election Reported Likelihood of Voting on Election Day

While these are only verbal representations of voters' forecasts of their likely behaviour, this variable looks much closer than post-election reported vote to measuring something that would aggregate to the $67 \%$ voting rate found in the actual election. Closer, but still a ways off, of course, since $78 \%$ claim to be certain to vote. However, we surmise that this distribution is still biased in a more politically-engaged, duty-bound direction, as compared with the true population distribution of this LV variable. We believe that those unlikely and certain not to vote make up at least $10 \%$ of the Canadian voting-eligible population, respectively, not $2 \%$ and $4 \%$. We assume also that there are more than the reported $17.5 \%$ in the 'Likely' category. This bias is important because we expect stronger effects of competitiveness on those who are likely or unlikely to vote and if we estimate effects with these categories underrepresented, we will effectively bias toward zero the estimate of the total effect of competitiveness on turnout in the population. (By contrast, we might over-estimate the effect of strategic voting, because it is more common among the most politically engaged (Merolla \& Stephenson, 2007).)

We expect that these pre-election statements about the likelihood of actually voting (LV) are correlated with voters' sense of Duty to Vote and that this is relevant for our analysis given the powerful effect of duty not just on voting but as a moderator of the influence of other determinants of turnout: As (Blais \& Achen, 2018) argue, any influences on the costs and benefits of voting are likely to have a much stronger impact on those who do not consider voting a duty. Table 2 shows that among those certain to vote, $81 \%$ see voting as a duty, while in the other categories moderate to strong majorities feel that voting is a choice. Considering voting a duty appears to be correlated with doing the post-election survey, with $75 \%$ of those 
who did the post-election interview considering voting a duty, in contrast to only $69 \%$ of those who did not do the post-election wave.

In our analysis below, we therefore estimate effects separately for those who consider voting a duty versus a choice. As we would expect (Blais 2018), we always find much stronger effects from competitiveness to turnout among those who consider voting a choice. ${ }^{1}$

The link between seeing voting as a duty and doing the post-election survey demonstrates the specific problem with the use of the post-election turnout measure of reported vote (RV): it contains too high a proportion of people who see voting as a duty and are therefore less susceptible to deterrents to voting. It also substantiates the general problem of measuring turnout with surveys, whereby our estimates will almost certainly underestimate the effect of competitiveness on turnout because we end up with an unrepresentatively duty-bound sample. Our analysis is therefore directed to demonstrate the existence of an effect of competitiveness on turnout rather than a precise estimate of the size of that effect.

CES2019 Likelihood of Voting and Duty

\author{
Certain to vote \\ Likely to vote \\ Unlikely to vote \\ Certain not to vote
}

Total
\% Saying Voting is

81

41

13

18

71
$\mathrm{N}$

25747

5191

1184

513

32635

Table 2: Voting as Duty versus Choice, by Pre-election Likelihood of Voting

\section{Inferring Preferred Party (Separate from Vote Intention)}

In the Canadian voting system, voters cast votes for individual candidates who, for the most part, are associated with political parties. Although some studies have attempted to determine to what extent a voter is primarily motivated to vote based on party affiliation vs individual candidate characteristics, it is nonetheless impossible to disentangle these considerations when observing an individual voter's ballot. Henceforth, we treat an individual voter's preferred choice as functionally equivalent to a Preferred Party (PP). We infer for individual voters what their Preferred Party is based on their responses to the Party and Leader feeling thermometers. $78 \%$ of respondents gave consistent responses here, in that their preferred leader was from the same party as their preferred party. For the $22 \%$ of voters who gave conflicting responses to this question, we averaged the scores given by a voter to each party and its leader, and took the party with the highest average score as the voter's PP. ${ }^{2}$

We also use the voter's pre-election vote intention and their post-election reported vote to check consistency with results using preferred party. We are forced to use the PP measure more extensively because the vote intention and reported vote were questions that were not asked to those who said they were certain not to vote or who said they didn't vote, respectively. The PP measure is also key to our determination of who has voted strategically.

\footnotetext{
${ }^{1}$ The question is: "People have different views about voting. For some, voting is a duty. They feel that they should vote in every election. For others, voting is a choice. They only vote when they feel strongly about that election. For you personally, is voting first and foremost a Duty or a Choice?"

${ }^{2}$ The 'feeling themometer' questions take this form: "How do you feel about the federal political parties [leaders] below? Set the slider to a number from 0 to 100, where 0 means you really dislike the party and 100 means you really like the party[leader]".
} 


\section{Measuring the Competitiveness of the Voter's Preferred Party}

We use both subjective and objective measures of the competitiveness of each survey respondent's preferred party.

The subjective measures use a question asking for the voter's raw estimate of the "chances" of each party winning the riding, on a zero to 100 scale. $^{3}$

If the parties are ranked from top to bottom based on these perceived probabilities, our $\mathrm{C}_{\text {subj }}$ score corresponds to the rank a voter gives their PP. This ranges from first (1) - most likely to win the riding - to fifth (5). We note that there is a great deal of wishful thinking among voters, such that, as Figure 3 shows on the x-axis, nearly two-thirds of those surveyed considered that the party they intended to vote was most likely, or at least tied for most likely, to win the riding, when, in fact, slightly less than $50 \%$ of voters will realistically see the party they intend to vote for win the riding.

Objective measures of competitiveness for an individual voter are based on the margin of loss or victory of the voter's PP in the riding in either the previous (2015) election. While the previous election is an imperfect guide to the current situation in the riding, it is a good proxy for the information a voter could potentially have about the relative chances of each party and is a standard variable included in studies of strategic voting in FPTP systems.

\section{Defining Strategic Voting}

Strategic Voting (SV), in the context of a Single Member Plurality voting system, refers to a voter not casting a vote for their sincerely most-preferred party or candidate, typically because they feel that their PP does not have a sufficient chance to win, andinstead voting it for another party or candidate who they feel has a stronger chance of defeating a lesser-liked alternative. The intent is to minimize a so-called 'wasted vote' - i.e., one that has no effect on the outcome of the election.

We therefore categorize a voter as intending to vote or having voted strategically if their vote intent or their reported vote:

1. does not match their preferred party; and

2. the voter's preferred party is outside the top two in the chances of winning the district;

3. and the party they intend to vote for or did vote for was placed in their estimate of the top two parties' chances locally.

Using this definition, we find strategic voting by $7.1 \%$ of respondents to the post-election questionnaire who voted and who ranked the parties' chances of winning the local seat. This estimate is above the level detected in studies of plurality elections, particularly in Canada, where estimates have ranged from $2 \%$ to $5 \%$ (Blais, 2002; Blais et al., 2009; Blais \& Gschwend, 2010; Blais, 2004; Blais et al., 2001; Merolla \& Stephenson, 2007). However those levels pre-date the emergence of a Green Party competitive nationally and in many districts, plus the recent entrance of the People's Party; below we show that voters who preferred those two parties made up $60 \%$ of strategic voters in 2019, such that the rate of strategic voting in the four other parties (Liberal, Conservative, NDP, BQ) matches previous estimates perfectly.

\section{Assessing the Impact of Competitiveness on Intention to Vote}

To evaluate the impact of competitiveness on voters' intention to vote (LV), we use various techniques to estimate the difference in the voters' expected response (certain to vote, likely to vote, unlikely to vote, or

\footnotetext{
${ }^{3}$ The question is: "For each of the parties below, how likely is each party to win the seat in your own local riding? Use the slider to place the party's chances from 0 (No chance at all of winning your riding) to 100 (Absolutely certain to win your riding)"
} 
certain not to vote) as a function of the subjective and objective measures of the competitiveness of the parties. We often differentiate between voters who see voting primarily as a duty versus those who see it as a choice. We use ordered logistic models to evaluate the effect of competitiveness on LV and evaluate the null hypothesis that the distribution of $\mathrm{LV}$ is independent of competitiveness.

\section{Results}

We present results as a series of figures. It bears repeating that the post-election reported vote measure is so problematic that most of our analysis is devoted to the Likely Vote measure.

\section{Effects of Competitiveness on Intention to Vote:}

Figure 1 shows voters' self-reported Likelihood to Vote (LV), measured pre-election, by the party they intended to vote for. Recall that the vote intention question was not asked to those who said they were certain not to vote, so the bars include only the Certain to Vote, Likely to Vote, and Unlikely to Vote responses. The figure shows that supporters of the traditionally 'third' or 'minor' parties are significantly less likely to be certain to vote, as compared to those who intended to vote Liberal or Conservative. (The BQ result is an exception that is in fact consistent with the patterns we see below because where it contests seats, it is usually among the top two).

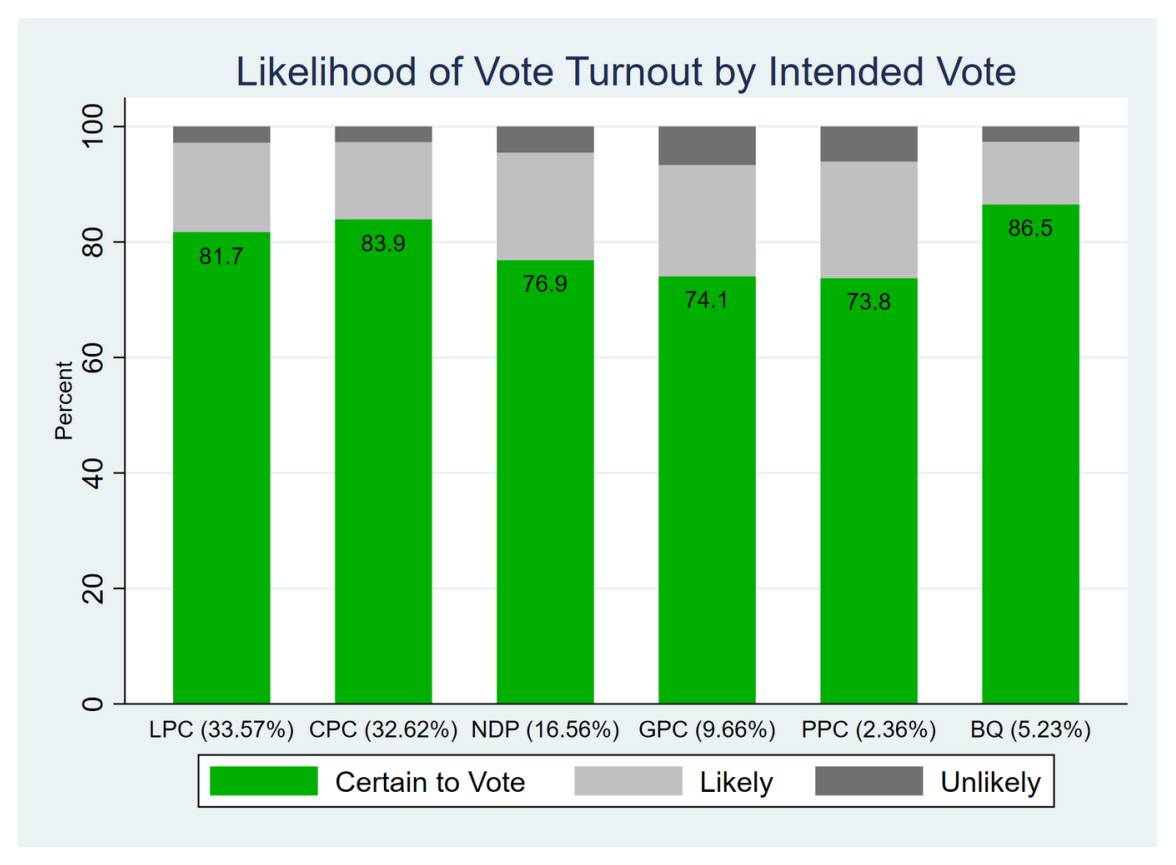

Figure 1: Canadian Election Study, 2019 - pre-campaign wave

In Figure 2 we separate respondents based on their response to the Voting is a Duty or a Choice question. As with all the analyses presented here, the differences in LV are much stronger among the voting-is-a-Choice people (29\% of the sample) and virtually non-existent among the Voting-is-a-Duty people (71\%), as Blais 
and Achen's argument would lead us to expect (Blais \& Achen, 2018). The voting-is-a-Choice citizens who support the NDP, Greens, or CPC are about $10 \%$ less likely to be certain to vote, and about $6 \%$ more likely to be unlikely to vote, than supporters of the Liberals and Conservatives. While this is suggestive, it is not direct evidence that it is the competitive position of these parties that is deterring voting among their supporters.

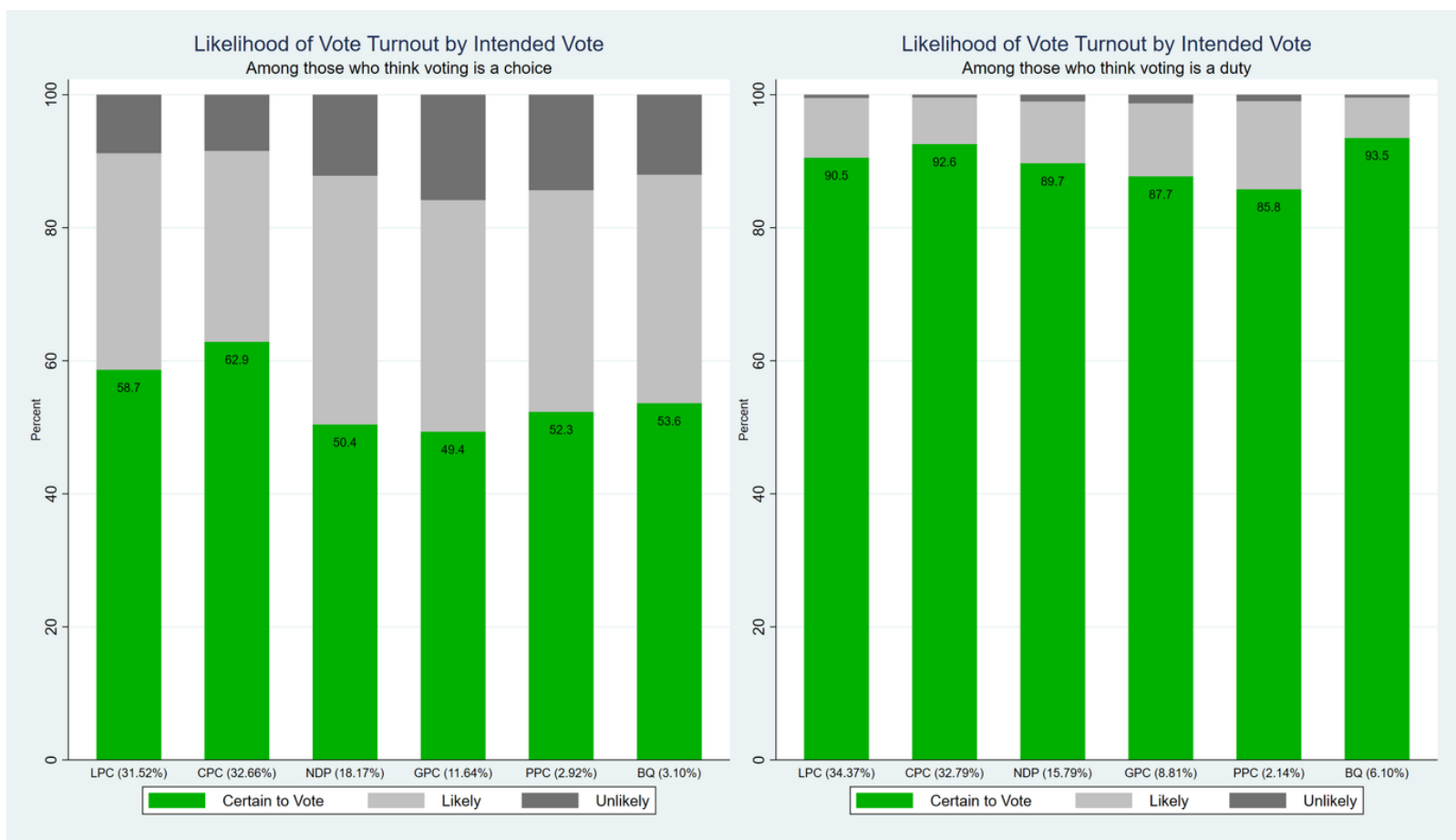

Figure 2: Canadian Election Study, 2019 - pre-campaign wave

In the next figure (Fig. 3), we show the same LV proportions but this time by the respondent's own placement of the local chances of the party the voter intended to vote for, relative to other parties. (For example, an NDP voter who gave the CPC a local chance of winning of 60, Liberals 50, and NDP 30 would be classified into the Rank 3 group). In Figure 3 we see a decline in Certain to Vote from $84.4 \%$ and $82.7 \%$ for the top two parties down through $78.1,77.5 \%$, and $66.2 \%$ for parties outside the top two. The fact that the gap widens more between the second and third ranks (4.6\% difference) rather than between first and second (1.7\%) is further suggestive evidence that competitiveness is truly driving the observed pattern. In Figure 4 we again see that this effect is stronger among the voting-is-a-Choice respondents. 


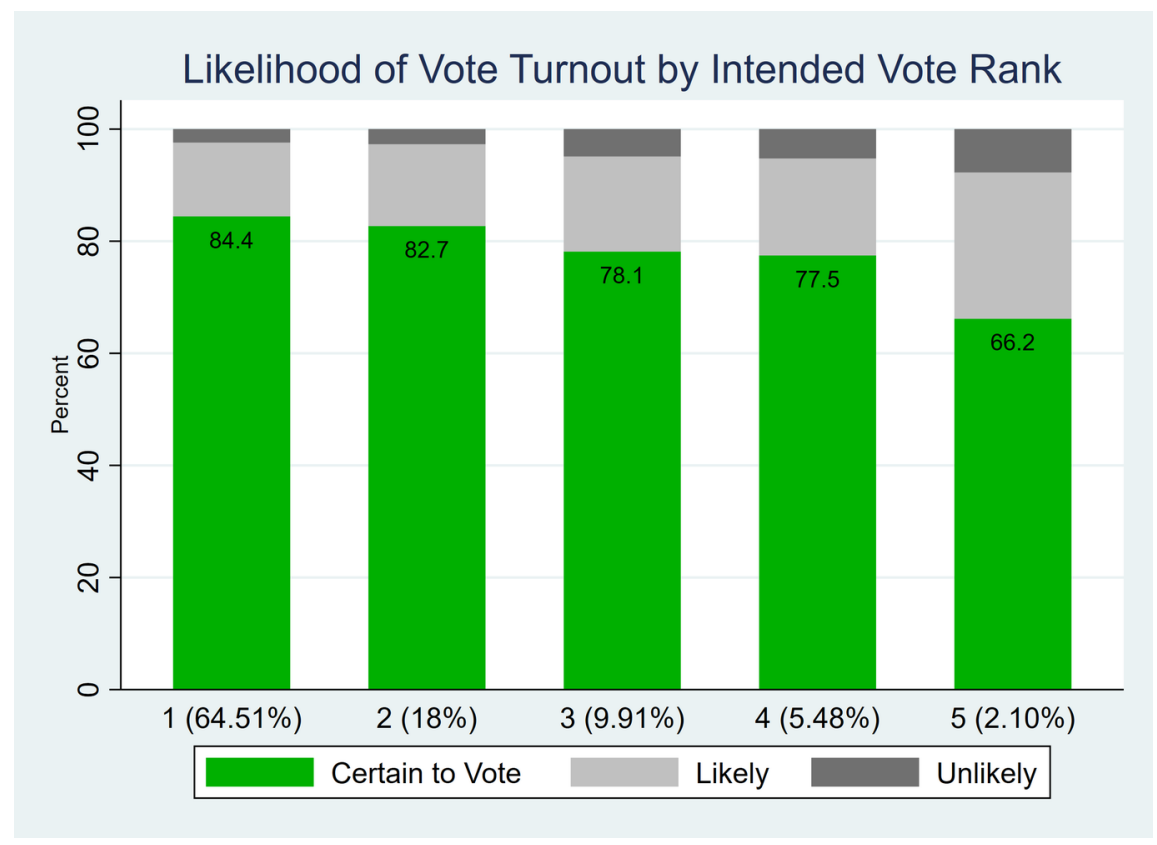

Figure 3: Canadian Election Study, 2019 - pre-campaign wave

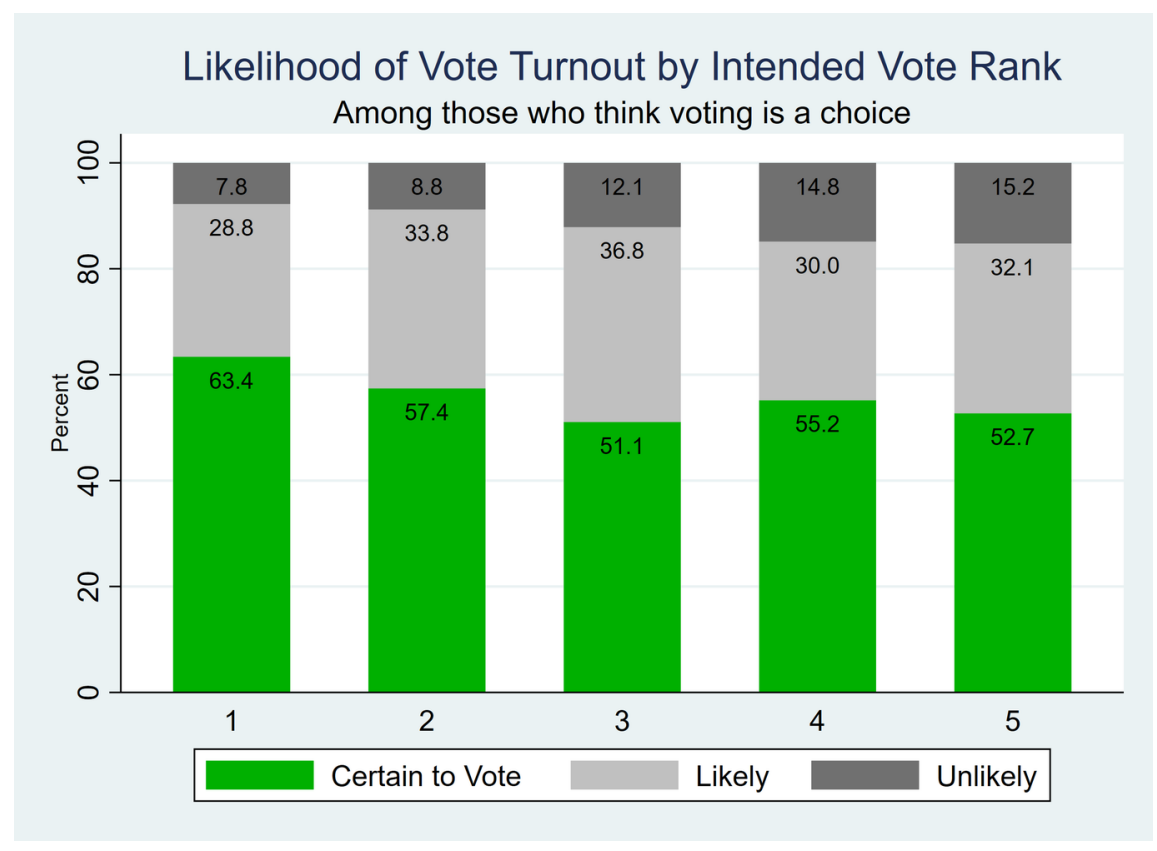

Figure 4: Canadian Election Study 2019 - pre-campaign wave

Note that Figure 3 shows that close to $65 \%$ of the sample thinks that their party has the best chance of winning the riding. This is clearly at odds with reality, given that only about $50 \%$ of votes cast are cast for the candidate that wins the seat. For the 2019 federal election, the percentages were actually $49.0 \%$ (of voters who voted for a candidate who ended up representing the riding in Parliament), and 26.7\%, $14.5 \%$, 
$6.7 \%$ and $2.3 \%$ for vote ranks 2 through 5 , respectively. The overestimate probably reflects both a sample selection bias - where people who support winning parties are more likely to be satisfied with politics and do the survey - and widespread wishful thinking. For our purposes, we simply wish to emphasize that more Canadians should be in the bars toward the right side of these figures than are indicated in the parentheses on the $\mathrm{x}$ axis that show the proportions.

In Table 3 we do a statistical test of the differences visible in Figure 3, based on predicted probabilities after an ordered logit estimation. The table indicates that there are strongly significant differences between all different ranks except 4 versus 3 . That, and the finding that the next weakest contrast (but still significant) is 1st versus 2nd, is further evidence in favour of our claim that it is the second-place to third-place difference that really pushes voters away from the polls. ${ }^{4}$

\section{Contrast of Predicted Marginal Probabilities of "Certain to Vote"} by Rank of Intended Vote (VI)

VI Rank
2
3
4
5
3
4
5
4
5
5

$\begin{array}{ccccc} & \text { VI } & \text { Con- } & \text { Std. } & \text { ra- } \\ & \text { Rank } & \text { trast } & \text { Err } & \text { tio } \\ \text { vs } & 1 & -0.02 & 0.01 & 2.61 \\ \text { vs } & 1 & -0.07 & 0.01 & 7.11 \\ \text { vs } & 1 & -0.07 & 0.01 & 5.96 \\ \text { vs } & 1 & -0.19 & 0.02 & 8.57 \\ \text { vs } & 2 & -0.05 & 0.01 & 4.61 \\ \text { vs } & 2 & -0.06 & 0.01 & 4.22 \\ \text { vs } & 2 & -0.17 & 0.02 & 7.58 \\ \text { vs } & 3 & -0.01 & 0.01 & 0.51 \\ \text { vs } & 3 & -0.12 & 0.02 & 5.2 \\ \text { vs } & 4 & -0.11 & 0.02 & 4.61\end{array}$

note: Contrast is how much less likely the voter is to say "Certain to Vote" when ranking

the party in the first column versus the second column of ranks

Table 3: Contrasts of Predicted Probabilities of "Certain to Vote" after Ordered Logit Estimation: LV as a function of Local Chances Rank of Intended Vote Party (note: ratio is ratio of the contrast to its standard error)

\section{Objective measures of competitiveness of preferred party}

So far, these analyses use our subjective measures of competitiveness, so we turn now to objective ones. Recall that we want to see if voters' wishful thinking about their party's chances is possibly suppressing the link from perceived chances to vote turnout, while voters are in fact responding powerfully to objective information despite it not factoring into what they tell us about their party's chances of winning.

The simple version of the analysis is that $82.5 \%$ of voters who intended to vote for a party that had lost the riding in 2015 were certain to vote, compared with $85.7 \%$ of those whose party had won the seat last time. This is only a 3.2 percentage point difference, but we interpret this as potentially keeping $3.2 \%$ of the

\footnotetext{
${ }^{4}$ We replicated these analyses using the preferred party rather than the intended vote (see above for measurement details). The patterns were weaker because the preferred party measure is a less precise measure of voters' overall preferences, partly due to conflicts between preferred party and preferred leader, but mostly because some respondents appear to have breezed through thermometer question, with respondents most committed to voting doing them more conscientiously and therefore appearing disproportionately among those who have a preferred party measurement. These analyses do confirm, however, that the small number of Certain-Not-to-Vote people increases as these people's preferred party is less and less competitive in the riding.
} 
electoral from going to the polls simply because the party they prefer did not win the seat last time. And while small, this difference is highly significant, with a $95 \%$ confidence interval of $2.3 \%$ to $4.1 \%$.

To see this in more detail, In Figure 5 we place voters in bins according to how the party they preferred in 2019 had done in the riding in 2015. The bins range from a loss of nearly 80 points (left side) to a victory of that same margin (right side). Examples of losers by more than 70 points are Green Party supporters in Cape-Breton Canso or Red Deer-Mountain View, NDP and Conservative supporters in Bonavista-BurinTrinity, and even Liberals in Battle River-Crowfoot. The steady increase in the green bars in Figure 5 from about 78 per cent to around 85 per cent shows that voters who preferred parties that lost by a large margin were dissuaded from voting, whereas voters who were 'winners' were more likely to say they were certain to cast a ballot. When we test this statistically we find a significant effect whereby an additional positive ten points on the margin of loss/victory pushes a Voting-is-a-Choice citizen out of the certain-to-vote category by nearly a full percentage point, with the effect for Duty voters about one-quarter as big.

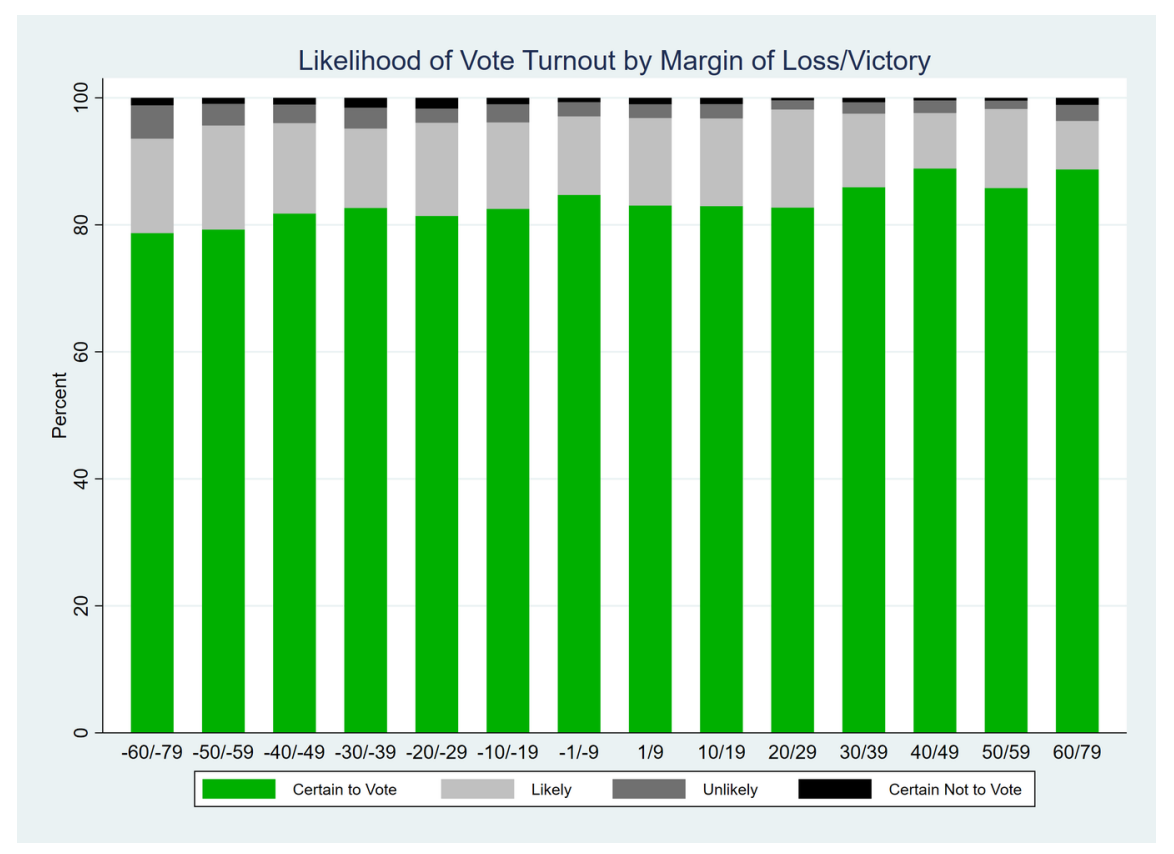

Figure 5: Canadian Election Study, 2019 - pre-campaign wave

In Figure 6 we show this pattern for only the Choice voters, and it shows a steeper gradient. In fact, the gradient is not very steep for losers; it appears that most of the effect is simply from supporting a party that lost. In statistical analysis (not shown) we see a significant effect of supporting a losing party in the previous election that pushes people out of the certain-to-vote response by about $3.6 \%(\mathrm{p}<.039)$, with the margin of loss adding only slightly to the deterrent effect. 


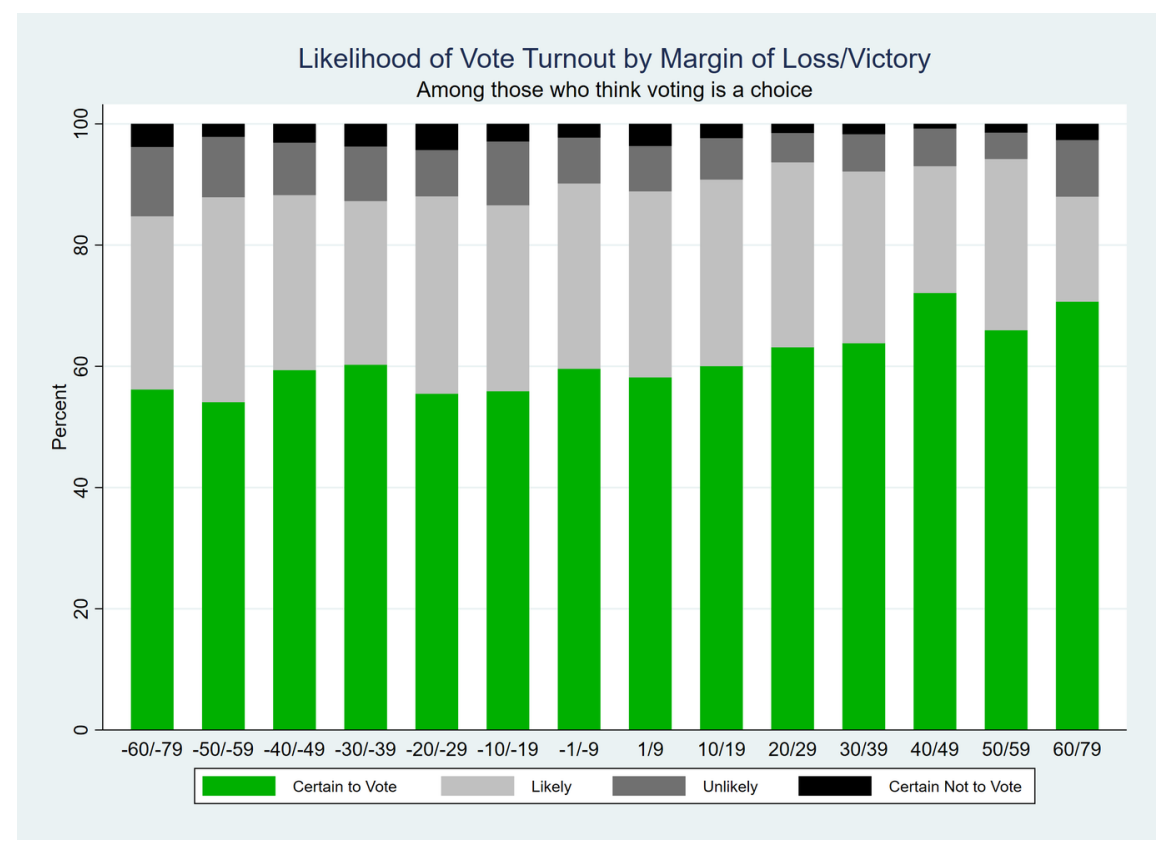

Figure 6: Canadian Election Study, 2019 - pre-campaign wave

After showing the effects on LV of both subjective and objective indicators of the party's chances, it is useful to show that voters' estimates of the parties' local chances are strongly related to the results of the previous election (Blais \& Bodet, 2006). Regressing the voter's estimate of their intended-vote party's chances on variables measuring, separately, that party's margin of victory or loss in 2015, gives:

$$
\text { Chances }=74.7+.30(\text { margin of victory })-.57(\text { margin of loss })
$$

with an $\mathrm{R}^{2}$ of .30 (p-values for coefficients and F-test $<1 \mathrm{e}-100$ ). Despite the tendency to wishful thinking - evidence is the constant at 75 ! - voters base much of their judgment of their party's chances on its showing in the previous election. So voters whose party finished third or worse last time are significantly less likely to say they are certain to vote.

\section{Statistical Test of Competitiveness on Turnout}

We estimated ordered logit models where the vote likelihood (LV) is the dependent variable and the rank of the voter's party (intended vote) is the independent variable, interacting this with the duty-vs-choice variable (see tabular results in Appendix). Generating predicted marginal effects, among the Choice voters, we find that a voter who thinks her vote-intention party has the second-best chance of winning the seat is $4.9 \%$ less likely to be certain to vote than an otherwise-similar voter who thinks her vote-intention party has the best chance of winning the riding $(\mathrm{p}<.006)$. Voters who ranked their party third were $9.7 \%$ less likely to be certain to vote than those who ranked their party first $(\mathrm{p}<.00001)$ and for those who ranked their party fourth the estimate is $6.7 \%(\mathrm{p}<.018)$. These effects of the competitiveness of the voter's chosen party on their propensity to vote are highly significant, though these effects are largely concentrated on the $30 \%$ of the electorate - roughly 7.5 million registered voters - who consider voting a choice. Voters who view voting as a duty go to the polls at roughly the same rates regardless of whether their party has a decent chance of winning or is sure not to win. 


\section{The Number of Affected Voters}

We sum this up by calculating an estimated total number of voters who are moved from the certain to vote category to another category of the LV variable in the following way:

1. The total number of eligible voters in the 2019 Canadian federal election $(25,939,742)$

2. multiplied by 0.29 (Voting-is-a-Choice people only)

3. multiplied by the sum of each of the non-first-rank-of-PP proportions among Choice voters multiplied by that rank's estimate of how much less likely that rank is to vote as compared to the first-rank (the $0.049, .097,0.067$, [and 0.048], from above),

which results in

$25,939,742 * 0.29=7,552,525$ (Choice Voters) and

$7,552,525 *(0.168 * 0.049)+(0.109 * 0.097)+(0.0593 * 0.067)+(0.035 * 0.048)=$

$\mathbf{1 8 3 , 9 8 7}$ Voters who would be "Certain to Vote" if they were to rank their party first but who are in fact less than Certain to Vote because they rank their preferred party second through fifth.

\section{Estimating Realistic Turnout Levels}

Because the reported vote from the post-election survey wave is such an overestimate of the true level of turnout, we wish to use our expert judgment to place probabilities on casting a vote, given a person's statement of the likelihood of voting (LV variable), and to make an educated guess about the true distribution of the likely voting categories in the full Canadian voting-age population.

Our basic assumption is that in the Canadian Election Study survey data, where respondents are undoubtedly more interested in politics than the general population (Breton et al., 2017), the Certain to Vote category is overestimated and the average reported vote among all of the LV categories are too high. In Table 4 we propose our corrections, aiming to have our adjusted probabilities add up to a total turnout of $67 \%$, which matches the actual turnout in the 2019 federal election.

Using the respondents who reported (in the post-election wave) whether or not they voted, we see in the top half of the table that with the distribution of the LV categories, multiplied by their respective probabilities of reporting having voted, we have a turnout of $92.8 \%$.

We begin (in the bottom half of the table) by increasing the "Certain Note to Vote" and the "Unlikely to Vote" categories to $10 \%$ of the population each. We increase the "Likely to Vote" category from 13 to $20 \%$ of the voting-age population. And thus our assumption is that the "Certain to Vote" people occupy $60 \%$ of the population rather than the $83 \%$ they constituted in the post-election survey. To be clear: these are expert judgments, assumptions only. But we feel that they are reasonable estimates of the distribution of the $\mathrm{LV}$ variable in the population.

We then assign assumed probabilities of voting to each of the categories. Note that we are reducing the probabilities across the board. In the post-election survey, among those who said they were "Certain Not to Vote", one in five reported voting! The reported vote proportions in the second column of the top half of the table are incontrovertibly overestimates of the population values. So we specify that the four groups vote at a rate of $5 \%, 20 \%, 60 \%$, and $88 \%$ respectively.

Multiplying through, we achieve a turnout rate of $67 \%$ with these assumptions. We then derive weights for our regression analysis (below), so that estimates of the effect of competitiveness on turnout are not based on a sample where Certain-to-Vote voters represent an overly high proportion of the sample. 
Corrected Vote Probabilities

for Pre-election Vote Likelihood Categories

Corrected by Assumption

Target Vote Turnout from Elections

Canada $=67 \%$

From Canadian Election Study 2019

\section{Certain Not To Vote \\ Unlikely to Vote \\ Likely to Vote \\ Certain To Vote}

note: Proportion(CES) is only among

respondents who did the PES survey

Correction Assumptions

$\begin{array}{cccc}\begin{array}{l}\text { Pro- } \\ \text { por- } \\ \text { tion }\end{array} & \begin{array}{c}\text { Prob(ReportedProd- } \\ \text { Vote) }\end{array} & \text { uct } & \begin{array}{c}\text { Proportion } \\ \text { of Voters }\end{array} \\ 0.02 & 0.2 & 0.0 & 0.0 \\ 0.03 & 0.39 & 0.01 & 0.01 \\ 0.13 & 0.8 & 0.1 & 0.11 \\ 0.83 & 0.98 & 0.81 & 0.88 \\ & \text { Turnout } & 0.93 & \end{array}$

(1)

$\begin{array}{cccccc} & \begin{array}{c}\text { Pro- } \\ \text { por- } \\ \text { tion }\end{array} & \text { Prob(Vote) } & \begin{array}{c}\text { Prod- } \\ \text { uct }\end{array} & \begin{array}{c}\text { Proportion } \\ \text { of Voters }\end{array} & \begin{array}{c}\text { Implied } \\ \text { Weights }\end{array} \\ \text { Certain Not To Vote } & 0.1 & 0.05 & 0.01 & 0.01 & 6.71 \\ \text { Unlikely to Vote } & 0.1 & 0.2 & 0.02 & 0.03 & 3.82 \\ \text { Likely to Vote } & 0.2 & 0.6 & 0.12 & 0.18 & 1.57 \\ \text { Certain To Vote } & 0.6 & 0.88 & 0.53 & 0.78 & 0.72 \\ & & \text { Turnout } & 0.67 & \end{array}$

Table 4: Vote Probabilities Corrected by Assumption

Based on these assumptions, we use OLS regression where these turnout probabilities, imputed to each respondent based on their LV responses, are the dependent variable, and the voter's rank of their preferred party are dummy independent variables. Figure 7 graphs predicted probabilities of voting using the regression results, for Duty and Choice voters respectively. While there is a moderate statistically significant effect in the Duty group, the choice group shows a much steeper decline in the propensity to vote as the voter thinks her party is less competitive relative to the other parties in the riding. The estimates range from $54 \%$ among Choice voters who think their party will win, down to $44 \%$ among those who put their PP in 4 th place. 


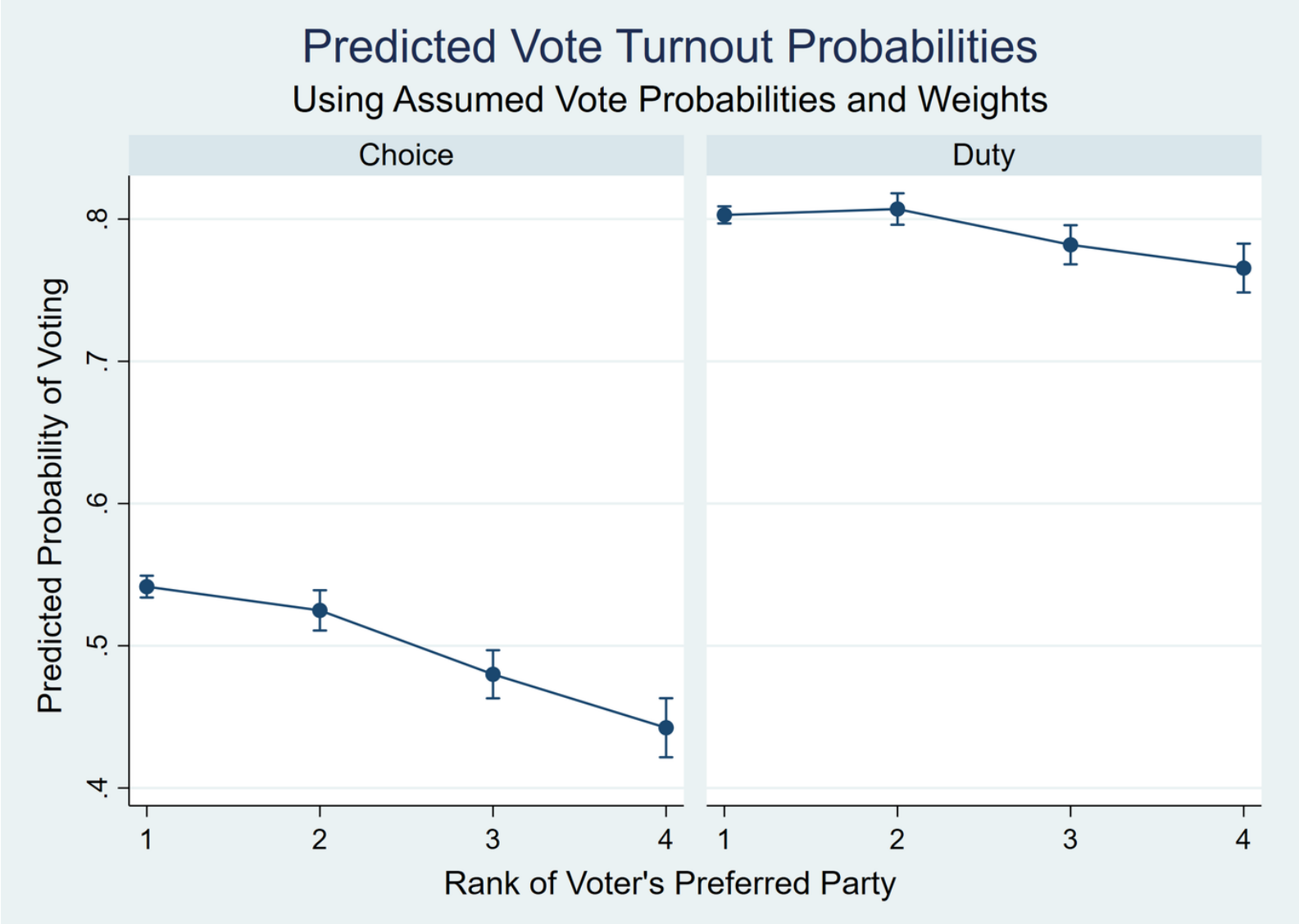

Figure 7: Canadian Election Study 2019 data

While these probabilities of turnout are based on our best guess about the proportions of these groups in the population, as well as their propensity to vote, and these estimated voting rates correspond better to reality, the drop-off in probabilities is roughly what we saw with the original LV variable. The value of the exercise is to present estimates that aggregate to the actual voter turnout of $67 \%$ rather than the survey's reported turnout of $92 \%$ and to show that for some voters (Choice voters), the difference may be moving them from a few points above $50 \%$ likely to vote down to a few points below $50 \%$.

The fundamental conclusion from the accumulation of analyses is that if the only thing we know about a voter is that they rank their preferred party third or lower in chances of winning the riding and they think voting is a choice rather than a duty, they are probably about $5-10 \%$ less likely to turn out on election day. The implication is that hundreds of thousands of Canadians are not voting at all - not expressing their political preferences - because they think their preferred party has a poor chance of winning the local seat. In effect, a structural aspect of the single-member-district plurality-winner voting system used in Canada - the fact that only the top vote-getter in a riding is elected - dissuades a significant proportion of supporters of other candidates from voting at all.

Furthermore, we can observe that the deterrent effect is of course not distributed equally across parties. Table 5, looping back to the point made by Figure 1 shows the average chances rank of the parties. Supporters of the NDP, Green Party, and People's Party of Canada rank their party's chances significantly lower than supporters of the Conservatives, Liberals, and BQ. The result, of course, is that one effect of the First-Pastthe-Post electoral system's famous "psychological effect" (Duverger, 1957) is to push certain parties and 
their perspectives by keeping some of their supporters from going to the polls at all.

$\begin{array}{cc}\begin{array}{c}\text { Average Rank of Voter's Intended Party Vote } \\ \text { ranked by average rank }\end{array} \\ \text { Conservative } \\ \text { Liberal } \\ \text { BQ } & 1.3 \\ \text { NDP } & 1.5 \\ \text { Green } & 1.5 \\ \text { PPC } & 2 \\ \end{array}$

Table 5: Canadian Election Study 2019, pre-campaign wave

\section{Effects of Competitiveness on Strategic Voting}

We turn now to consider the effect of the local competitiveness of parties on whether or not voters vote sincerely for their most preferred choice. Before showing the distribution of strategic voting by preferred party, we offer Figure 8, displaying the actual reported party vote broken down by our preferred party measure. We use the standard colours associated with each party to show the voting behaviour of voters who preferred each of the five parties. Recall that PP is calculated based on respondent's feelings about parties and their leaders, so there may be other influences on desertion of that party, including the local candidates and short term policy dissatisfaction.

This figure shows clearly that supporters of the NDP, Green Party, and People's Party were much more likely than supporters of the two biggest parties to vote for a party other than the one they preferred $(30 \%, 52 \%$, and $57 \%$, respectively, vs $11 \%, 8 \%$ and $14 \%$ for the LPC, CPC and BQ, respectively; all differences except $\mathrm{BQ}$ vs Liberal and $\mathrm{PPC}$ vs Green are significant at $\mathrm{p}<.05)$ It is notable that this is not just a function of a crowding of parties on Canada's Left, since the Liberals seem to rarely desert their preferred party and the highest rate of voters casting a vote at odds with their preference is among People's Party supporters. The prima facie evidence from the patterns of non-preferred-party voting here is that strategic voting is alive and well in Canada. That is, a significant fraction of voters are for some reason voting for their second or third choice party, and these cross-over voters are disproportionately drawn from the parties with lower percentages of supporters in the ridings they contest. 


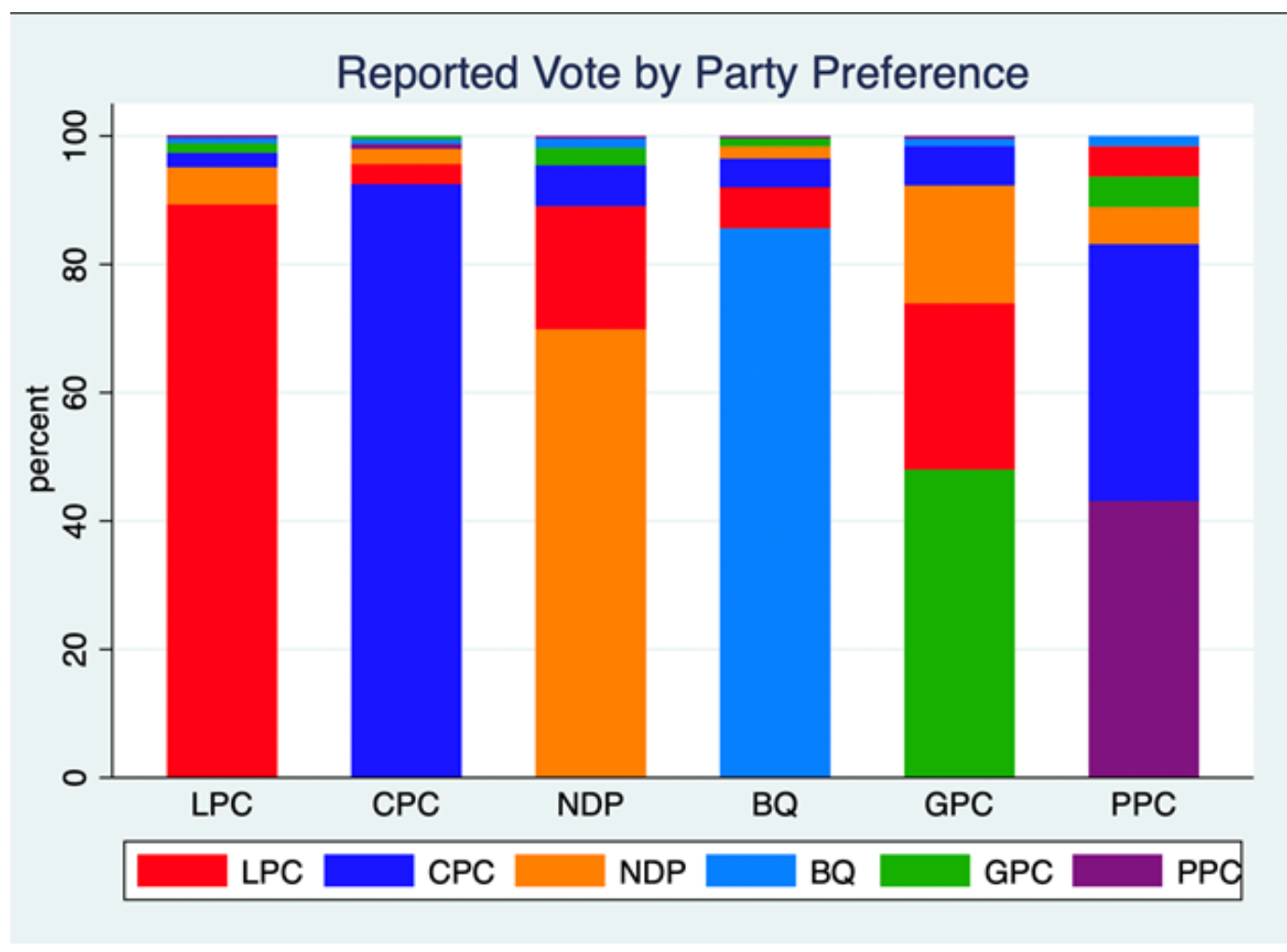

Figure 8: Canadian Election Study, 2019 - pre- and post-campaign wave

Table 6 shows our calculation of the rate of strategic voting by party preference. While not surprising, the table shows starkly that voters with particular party preferences are much more likely to go to the polls and mark a ballot for a party that is not their first choice. The first-past-the-post system induces rational, adaptive voting behaviour whereby a significant number of voters, predominantly those who support smaller parties, feel they cannot sincerely express their preferences for candidates, parties, and leaders. Obviously, this harks back to our Table 5, with those parties ranking their party lower in terms of its chances of winning the local riding. We nevertheless emphasize that voters supporting any party can be affected; even Liberals and Conservatives, in certain places, and if their judgment about their party's chances were not clouded by wishful thinking, would have good reason to vote strategically rather than sincerely. 
Strategic voting by Party
Preference

$\begin{array}{cccc}\text { Preferred Party } & \text { Rate of Strategic Voting } & \text { of All Strategic Voters } & \text { N } \\ \text { People's Party } & (\%) & (\%) & 55 \\ \text { Green Party } & 40.2 & 14.91 & 168 \\ \text { NDP } & 33.3 & 45.53 & 105 \\ \text { Liberal Party } & 14.6 & 28.46 & 28 \\ \text { Conservative Party } & 1.6 & 7.59 & 12 \\ \text { Bloc Quebecois } & 0.6 & 3.25 & 1 \\ & 0.4 & 0.27 & 369 \\ & & & (7 \%)\end{array}$

Table 6: Canadian Election Study, 2019 - pre- and post-campaign wave

Figure 9, finally, shows the rate of strategic voting by the chances rank of the voter's preferred party. Recall that our definition of strategic voting is that voters who rank their party's chances first or second have no reason to vote strategically. We see that once voters estimate the chances of their preferred party below second in the riding, a very large minority votes strategically, albeit these below-second-rank voters constitute only one in five respondents (who had a preferred party and reported voting).

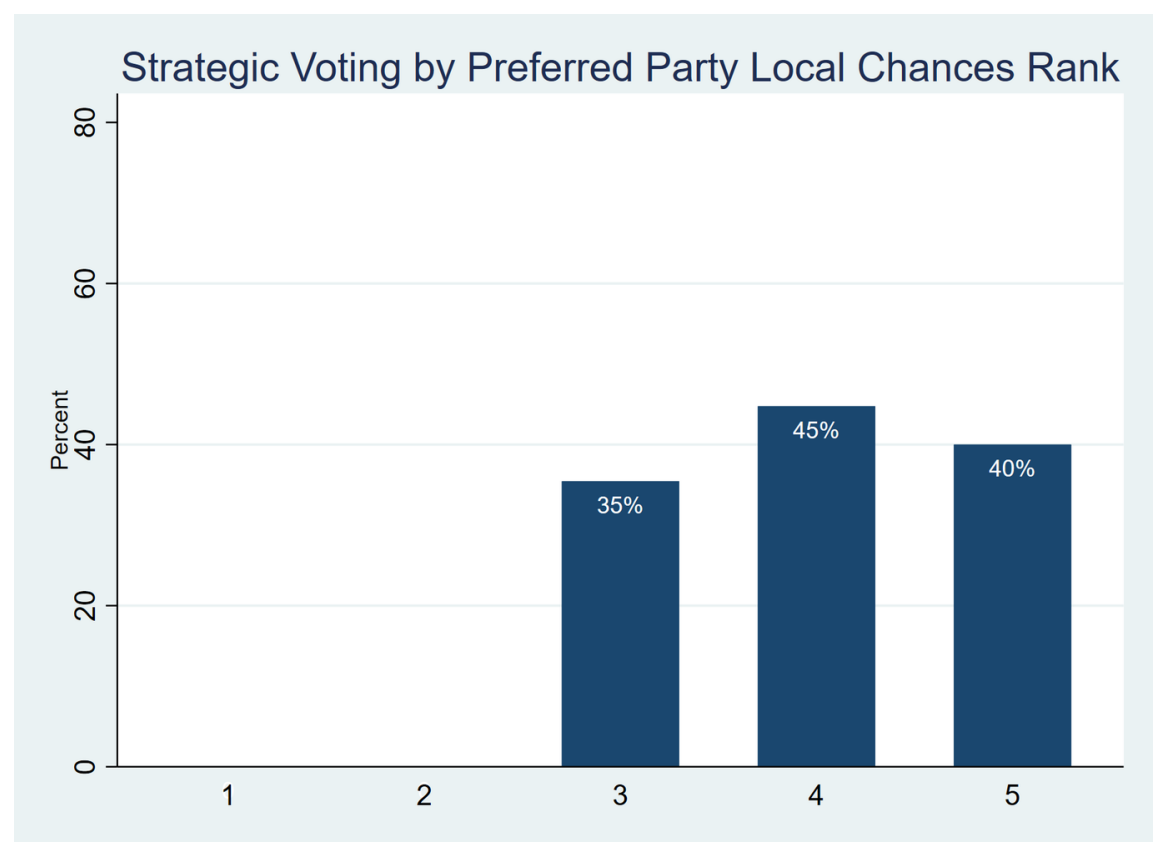

Figure 9: Canadian Election Study, 2019 - pre- and post-campaign wave

\section{Discussion and Conclusion}

For the most part, we answer our research questions in the affirmative. Our findings imply that because of single member plurality voting (FPTP) significant numbers of voters are dissuaded either from voting 
altogether, or, if they do vote, from voting honestly. Both intention to vote and reported voting decrease as a voter's preferred party is less competitive locally. In addition, voters engage more in strategic voting if their PP is not one of the top two contenders locally and this means that strategic voting is disproportionately concentrated among voters with distinct ideological preferences (i.e., those associated with geographically dispersed parties with lower levels of popular support than the largest parties).

This paper adds further depth and nuance to the widely acknowledged finding that the proportionality of the electoral system has an effect on rates of voting turnout. In much of that work, the implicit normative criterion is overall turnout, such that, while it is suggested that the turnout gap is produced by particular voters staying away from the polls, the concern is that any given citizen might be deterred from voting by the lack of competitiveness in their district. Here, we show that it is voters who hold minority political (party) preferences in the locale that are much more likely than voters with other preferences to stay away from the polls.

Even if the election results would be unchanged if these dissuaded voters both voted and voted sincerely because their parties almost never win - it is highly probable that the officially-reported levels of support for the parties that do win seats in Parliament is exaggerated relative to their support in the voting population, both because voters who support other parties simply don't bother to vote and because a number of the votes they did receive were not cast for the candidates or parties those voters actually preferred. Our contribution in this paper is to show that not only is this due to differential strategic voting across parties, but that turnout is affected as well.

Thus, the formal results of first-past-the-post parliamentary elections likely overstate the raw level of support for the leading parties, particularly for the one party that forms government, and so the government's legitimacy is arguably significantly lower than the formal voting results would imply. Moreover, many individual voters are likely less satisfied with democracy, and perhaps even feel that it is de facto unequal, because their votes are not as meaningful or effective as the votes of other citizens. Importantly, because citizens tend to stay put where they live, and both their preferences and patterns of electoral geography change only slowly, for a significant number of citizens this is a life-sentence: they are likely to feel deterred from voting over a long sequence of elections (Cutler \& Hooper, 2015).

The practical effect of the plurality electoral system with single-member districts is that a significant number of voters either are not participating at all or are not expressing their honest preferences in what is arguably the most fundamental and important democratic process - voting. Plurality, winner-take-all electoral systems have a cost: for large numbers of voters they detract from the satisfaction that their voice has been heard in the political system (Merkley et al., 2019), thereby likely undermining attachments to the polity and the legitimacy of the political system (Anderson et al., 2005)

\section{Limitations}

Our study is limited for the most part by the measurement of actual turnout, and even the propensity to vote, as discussed above. The problem is not just that turnout is overestimated by the survey questions (for various reasons), but rather that the selection bias involved in participation and attrition across the survey waves serves to weaken the estimate of the effect of competitiveness on turnout, relative to what it would be with perfect measurement in the full population. So while we cannot accurately calibrate the size of the effect involved, we believe that this study clearly demonstrates the existence of a strong effect of the parties' local chances of winning on their supporters' propensity to cast a ballot.

While our study uses only the 2019 Canadian Election Study data, the size of this survey is sufficient to allow us to precisely estimate the effects studied in the respondent pool. We do not believe there is anything atypical about the 2019 election, or, indeed, that Canada is atypical of plurality single-member-district systems. In short, from these data on one Canadian election, we are confident in generalizing the findings to all such systems that feature more than two parties competing at the district level. 


\section{Conclusion}

We have demonstrated that voters in Canada have a weaker intention to vote, vote at lower rates, and engage more in strategic voting when they believe their preferred party is less likely to win a local seat. This finding provides greater insight into the more widely-established finding that proportional voting systems tend to result in higher voter turnout than do plurality voting systems and provides evidence that plurality voting systems pose impediments to the full and honest participation of voters with political perspectives that happen to be in a minority in their electoral district.

\section{Appendix}

Estimates of Likely Vote by Rank of Local Chances of Intended Vote Party

Estimates of Likely Vote by Rank of Intended Vote Party

$\begin{array}{cc}\text { Ordered Logit Coefficients } & \\ & \mathrm{b} / \mathrm{se} \\ \text { Ranked Intended Vote 2nd } & -0.2 \\ & 0.07 \\ \text { Ranked Intended Vote 3rd } & -0.39 \\ & 0.08 \\ \text { Ranked Intended Vote 4th } & -0.27 \\ & 0.11 \\ \text { Duty } & 1.87 \\ & 0.05 \\ \text { Ranked Intended Vote 2 X Duty } & 0.19 \\ & 0.1 \\ \text { Ranked Intended Vote } 3 \text { X Duty } & 0.27 \\ \text { Ranked Intended Vote 4 X Duty } & 0.13 \\ & -0.17 \\ \text { Age } & 0.16 \\ & 0.03 \\ \text { cut1 Cut Points } & 0.0 \\ & -1.21 \\ \text { cut2 } & 0.07 \\ & 0.97 \\ \text { N } & 0.07 \\ \end{array}$

Table 7: 2019 Canadian Election Study, pre-election wave 


\section{References}

Polarization Number of Parties, and Voter Turnout: Explaining Turnout in 26 OECD Countries. (2017). Social Science Quarterly, 98(5), 1391-1405. https://doi.org/10.1111/ssqu.12366

Does proportional representation foster voter turnout?. (1990). European Journal of Political Research, 18(2), 167-181. https://doi.org/10.1111/j.1475-6765.1990.tb00227.x

The Impact of Proportional Representation on Turnout: Evidence from New Zealand. (1999). Australian Journal of Political Science, 34(3), 363-377. https://doi.org/10.1080/10361149950281

Electoral Systems, efficacy, and voter turnout. (2009). In The Comparative Study of Electoral Systems (pp. 109-134). Oxford University Press.

Candidate-centred electoral systems and voter turnout. (2017). West European Politics, 40(3), 516-533. https://doi.org/10.1080/01402382.2016.1271599

Electoral Systems and Turnout. (2006). Acta Politica, 41(2), 180-196. https://doi.org/10.1057/ palgrave.ap. 5500148

Choosing Electoral Systems: Proportional Majoritarian and Mixed Systems. (1997). International Political Science Review, 18(3), 297-312. https://doi.org/10.1177/019251297018003005

The Paradox of Proportional Representation: The Effect of Party Systems and Coalitions on Individuals' Electoral Participation. (2004). Political Studies, 52(3), 469-490. https://doi.org/10.1111/j.14679248.2004.00491.x

Electoral Competitiveness and Turnout in British Elections 1964-2010. (2015). Political Science Research and Methods, 5(4), 775-794. https://doi.org/10.1017/psrm.2015.67

Closeness Counts in Canada: Voter Participation in the 1993 and 1997 Federal Elections. (2002). The Journal of Politics, 64(2), 610-631. https://doi.org/10.1111/1468-2508.00143

Turnout and Closeness: Evidence from 60 Years of Bavarian Mayoral Elections. (2018). The Scandinavian Journal of Economics, 120(2),624-653. https://doi.org/10.1111/sjoe.12241

The conditional impact of winner/loser status and ideological proximity on citizen participation. (2016). European Journal of Political Research, 55(4), 767-788. https://doi.org/10.1111/1475-6765.12161

The Psychological Impact of Electoral Laws: Measuring Duverger's Elusive Factor. (1991). British Journal of Political Science, 21(1), 79-93. https://doi.org/10.1017/s0007123400006037

Turnout and the party system in Canada 1988-2004. (2007). Electoral Studies, 26(4), 735-745. https: //doi.org/10.1016/j.electstud.2007.08.002

Voter turnout and district-level competitiveness in mixed-member electoral systems. (2016). Journal of Elections Public Opinion and Parties, 26(4), 452-469. https://doi.org/10.1080/17457289.2016.1189919

How Do Voters Form Expectations about the Parties' Chances of Winning the Election?*.(2006).Social Science Quarterly, 87(3), 477-493.

Understanding Voter Turnout in Canada: What Data Do We Lack?. (2019). Canadian Parliamentary Review, 42.

Strategic voting in Canada: A Cross Time Analysis. (2007). Electoral Studies, 26(2), 235-246. https: //doi.org/10.1016/j.electstud.2006.02.003

Civic Duty and Voter Turnout. (2018). Political Behavior, 41(2), 473-497. https://doi.org/10.1007/ s11109-018-9459-3 
Why is there so Little Strategic Voting in Canadian Plurality Rule Elections?. (2002). Political Studies, 50(3), 445-454. https://doi.org/10.1111/1467-9248.00378

Voting Strategically in Canada and Britain. (2009). In Duverger's Law of Plurality Voting (pp. 13-25). Springer New York. https://doi.org/10.1007/978-0-387-09720-6_2

Strategic Defection Across Elections Parties, and Voters. (2010). In Citizens, Context, and Choice (pp. 176-191). Oxford University Press. https://doi.org/10.1093/acprof : oso/9780199599233.003.0008

Strategic Voting in the 2002 French Presidential Election. (2004). In The French Voter (pp. 93-109). Palgrave Macmillan UK. https://doi.org/10.1057/9780230523791_6

Measuring strategic voting in multiparty plurality elections. (2001). Electoral Studies, 20(3), 343-352. https://doi.org/10.1016/s0261-3794(00)00017-2

Telephone versus Online Survey Modes for Election Studies: Comparing Canadian Public Opinion and Vote Choice in the 2015 Federal Election. (2017). Canadian Journal of Political Science, 50(4), 1005-1036. https://doi.org/10.1017/s0008423917000610

Political parties, their organization and activity in the modern state. (1957). Muthuen.

Winners, Losers, and Electoral System Change. (2015). In Parties and Party Systems: Structure and Context (p. 261). UBC Press.

Having Their Say: Authority Voice, and Satisfaction with Democracy. (2019). The Journal of Politics, $81(3), 848-861$. https://doi.org/10.1086/702947

Losers' Consent. (2005). Oxford University Press. https://doi.org/10.1093/0199276382.001.0001 